\title{
Concepción celebró primeras 4.000 cirugías cardíacas
}

\author{
Roberto González Lagos
}

Equipo de Cirugía Cardiotorácica, Hospital "Dr. Guillermo Grant Benavente",

Facultad de Medicina, Universidad de Concepción, Concepción, Chile.

Con motivo de este significativo logro para nuestra cuidad y equipo médico, deseamos a través de esta carta compartir con la comunidad quirúrgica, cardiológica y médica en general, nuestra alegría y satisfacción.

En el mes de abril del presente año en el marco de la conmemoración de las primeras 4.000 cirugías cardíacas en Concepción, se realizó un acto de celebración en la Facultad de Medicina de la Universidad de Concepción en que se dictaron tres conferencias: los inicios de la cirugía cardíaca en Concepción; desarrollo de nuevos equipos en cirugía cardíaca; y presente y futuro del equipo cirugía cardíaca, que estuvieron a cargo de los cirujanos Alberto Gyhra S., Manuel José Irarrázaval L1. y Enrique Seguel S., respectivamente. La cirugía cardíaca es una especialidad relativamente joven. La primera cirugía con circulación extracorpórea fue realizada en 1953 por el doctor John Gibbon en Filadelfia 1,2. En Chile, la primera cirugía cardíaca de estas características fue en el hospital Luis Calvo Mackenna en 1957, por el equipo del doctor Helmuth Jaeger 3. Eran tiempos difíciles para nuestra especialidad, con resultados no siempre satisfactorios 4-6. Sin embargo, nuestros predecesores supieron perseverar y convencer a su generación de los beneficios para los pacientes.
A Concepción, la cirugía cardíaca llega impulsada por un grupo de pioneros a principio de los años 70, liderada por prestigiosos cirujanos cardiotorácicos de la capital de la Región del Bíobío como los doctores Hernán Goüet, Alberto Gyhra, Claudio Santander y Octavio Enríquez. Como en todas partes, aquí tampoco fue fácil, sin embargo, el convencimiento íntimo de estar haciendo lo correcto, permitió que esos cirujanos impusieran sus ideas y la especialidad se asentara en la ciudad. Desde los primeros años difíciles, en Concepción, en Chile y en el mundo, la cirugía cardíaca como especialidad se ha desarrollado vertiginosamente en sus técnicas y ha ampliado sus campos de acción. Como ejemplo, en los inicios de la cirugía cardíaca en nuestra ciudad se operaba un paciente al año y para este año nuestro objetivo alcanza los 500 pacientes.

Son 37 años de historia y son 4.000 diferentes historias que se han entrelazado al pasar por el pabellón de cardiocirugía. Celebramos un proceso, no siempre fácil; cada avance dado en estos años ha significado una importante dosis de convencimiento, negociación y sacrificio. También celebramos un número, 4.000 pacientes operados habla de un nivel de experiencia acumulada importante. Habla de un manejo colectivo afiatado y de equipos que saben lo que hacen. 
Actualmente el equipo del Departamento de Cirugía de la Facultad de Medicina de la Universidad de Concepción y del Hospital Clínico Regional "Dr. Guillermo Grant Benavente" de Concepción, está integrado por los cirujanos Aleck Stockins L, jefe del equipo, Emilio Alarcón C, Enrique Seguel S y Roberto González L, por el anestesista cardiovascular Patricio Cárdenas M. Además, por los perfusionistas Mauricio Bravo, David Bustos y Soledad González.

Pero lo alcanzado no lo han logrado los cirujanos cardiotorácicos, anestesistas cardiovasculares y perfusionistas por si solos. Operar un paciente significa mover un sistema que lo componen muchos y diferentes estamentos hospitalarios y unidades de apoyo. De hecho, cirugía cardíaca debe ser la especialidad quirúrgica que más apoyo necesita para poder hacer su trabajo bien.
Injustamente nos llevamos las loas nosotros, cuando existen unidades sin cuyo apoyo esta aventura sería impensable.

Tampoco olvidamos que la única razón por la que hacemos lo que hacemos es por una persona que está enferma y a la cual nosotros podemos tratar. El destino ha hecho que nuestras vidas se cruzaran con las de otras 4.000 personas. Influimos en forma relevante en algún momento de sus vidas, y muchas veces en el último. El esfuerzo no siempre fue suficiente. Sin embargo, nos queda el consuelo que siempre dimos todo lo que podíamos. Por eso, como equipo siempre agradecemos a esas 4.000 personas que, confiando en nosotros, pusieron sus vidas en nuestras manos ( $\mathrm{y}$ a otras tantas que vendrán).

\section{Referencias}

1. GIBBON JH JR. Application of a mechanical heart and lung apparatus to cardiac surgery. Minn Med 1954;37:171-85.;

2. GIBBON JH JR. Development of the artifical heart and lung extracorporeal blood circuit. JAMA 1968;206:1983-6.

3. JAEGER H, EIMBCKE F, TABOADA E. Consideraciones clínicas sobre 25 intervenciones intracardíacas a visión directa con circulación extracorpórea. Rev Med Chile 1958;86:704.

4. MORÁN S. Historia de la Cirugía Cardíaca. Rev Chil Cirugía
1997;49:733-7.

5. ZALAQUETT R. Y de cómo se llegó finalmente a la cirugía a corazón abierto. Un relato en 2 partes de pioneros, héroes y conquistadores del siglo pasado. Parte II. Rev Chil Cardiol 2000;19;119-12.

6. ZALAQUETT R. Cincuentenario de la máquina corazónpulmón: Un relato acerca de los pioneros y héroes y de las circunstancias que llevaron al gran invento que permitió el tratamiento y la cura de las enfermedades del corazón. Rev Med Chile 2003;131:1337-44. 